\title{
From Heartbreak to Heart Disease: A Narrative Review on Depression as an Adjunct to Cardiovascular Disease
}

\author{
Jahanzeb Malik $^{\mathrm{a}}$ Hamid Sharif Khan $^{\mathrm{a}}$ Faizan Younus $^{\mathrm{a}}$ Muhammad Shoaib $^{\mathrm{b}}$ \\ aRawalpindi Institute of Cardiology, Rawalpindi, Pakistan; bakistan Institute of Cardiology, Islamabad, Pakistan
}

\section{Keywords}

Myocardial infarction - Depression · Broken heart .

Cardiovascular disease

\begin{abstract}
Patients with cardiovascular disease (CVD) commonly have subclinical depression and are often delayed in their diagnosis. Literature suggests an increased association of depression and adverse cardiovascular events like myocardial infarction and heart failure. Prevalence of depression in developed countries is approximately $16.6 \%$, and it confers higher cardiovascular mortality even after attrition bias and confounding factors are eliminated. Pharmacological and cognitive-behavioral therapy have been extensively studied, and are generally safe and effective in alleviating depressive symptoms in patients with CVD. However, their impact on cardiovascular outcomes is still unclear. Results of randomized controlled trials have shown antidepressants, especially selective serotonin reuptake inhibitors, to be safe and effective for healing a "broken heart." This review outlines the prevalence of depression in patients with CVD, the pathophysiological mechanism causing cardiovascular events with depression, and a link between depression and CVD.
\end{abstract}

There is a wealth of literature explaining the precursor of CVD in depression, and like all chronic diseases, inflammation seems to be the culprit in this case as well.

(c) 2021 S. Karger AG, Basel

\section{Background}

A connection between depression and cardiovascular disease (CVD) is well established in the literature. Both of these are 2 very common diseases in developing and developed countries [1]. Sadness, like angina, is frequently described as chest heaviness or as a "broken heart." When comparing the contrast between 2 mechanisms of chest pain, it becomes clear that these perceptions are widely somatic feelings. Coronary artery disease (CAD) generally produces symptoms when there is at least $50 \%$ stenosis in 1 or more epicardial coronary arteries with or without acute coronary syndrome (ACS) [2]. Depression is exceedingly common in patients with CVD, and patients with depression and poor functional status have a higher risk of developing CAD.

The literature in the past 2 decades has acknowledged that not only depression is affiliated with CVD, but it also 
confers an increased risk of mortality and morbidity in patients with CVD [3, 4]. A study reported that mortality among patients with depression was largely associated with CVD [5]. Conversely, there is an increased propensity for myocardial infarction (MI) and heart failure in patients suffering from "heartbreak" [6]. Depression is also linked with a poor quality of life and noncompliance to treatment in these patients, leading to increased hospital visits and use of health services. A mathematical model predicted an elevated 12-month mortality in patients after MI who were diagnosed with syndromal depression [7].

Previously published reviews have discussed comorbid depression with CAD, and its effect on the prognosis in patients with CVD. However, in this review, we focus on the epidemiology and discuss the pathophysiological mechanism that links these 2 conditions. Although lifestyle factors play a pivotal role to stop progression and lead to the stabilization of CAD in such patients, it is not discussed in detail. We describe potential treatments and their effect on depression and CVD, including methods to detect subclinical depression in such patients.

\section{Epidemiology}

Depression and CVD are common. According to the National Comorbidity Study, the lifetime prevalence of depression is $16.6 \%$ [8]. It is higher in women, and subclinical depression is also common in primary care clinics. The overall cardiovascular risk of death is $4.7-6.4 \%$ among people without any cardiovascular risk factors and $20.5-29.6 \%$ among those with 2 or more risk factors. Diabetes mellitus, smoking, untreated hypertension, elevated low-density lipoprotein-C levels, and increased waist-to-hip ratio are some of the modifiable risk factors of CVD [9]. It is reported that depression is the second leading cause of disability after CVD. A meta-analysis has shown an increased risk of CVD by $26 \%$ among people with anxiety disorders [4].

The prevalence of depression among people with CAD is believed to be between 15 and 20\%, while in a metaanalysis of patients with decompensated heart failure, the prevalence of depression was $36 \%[10,11]$. The subclinical depressive symptoms often persist in patients with CVD secondary to inappropriate or inadequate treatment. Nonadherence is one of the major causes of disability in these patients.

A large study of 2,832 adults with no history of CVD who were diagnosed with a baseline depressed mode demonstrated an increased risk of fatal and nonfatal ischemic events [10]. One other study showed that even after elimination of attrition bias and controlling all the risk factors, depression is a risk factor for the development of CAD [12]. In a follow-up study of 2,299 patients, $3.7 \%$ of men and $4.6 \%$ of women had possible depression with CVD. In the same study, the odds ratio for CVD was 1.162 $(95 \%$ CI $1.096-1.231, p<0.001)$ for men and $1.107(95 \%$ CI 1.038-1.181, $p=0.002)$ for women [4]. Similarly, depression was a predictor of CAD (RR 2.12, 95\% CI 1.24$3.63, p<0.01)$ and MI (RR 2.12, 95\% CI 1.11-4.06, $p<$ 0.01 ) in male medical students enrolled in the Johns Hopkins University Precursors Study [13].

The EPIC-Norfolk United Kingdom Prospective Cohort Study enrolled 8,261 men and 11,388 women with no clinical manifestations of heart disease. After a followup of 8 years, patients with depression had 2.7 times the probability of dying from a cardiovascular event than participants who did not have depression [14]. This effect had no link with comorbid cardiovascular risk factors. A Danish Psychiatric Central Research Registry gave similar results. The data showed a positive association of depression with MI [15].

There is enough literature to suggest an effect of CVD on the risk of depression as it is frequently seen in patients with heart failure and atrial fibrillation [16]. Strikingly, depression causes a deleterious effect on ACS as well as chronic coronary syndrome. The American Heart Association recommends screening for depression in patients with established CAD or suspected CVD, indicating that early diagnosis and treatment of depression in patients with CVD is important [12].

\section{Pathophysiology}

Various biological factors have been implicated in patients with depression which can lead to CVD, but most of them are speculative at present and no significant literature is available in explaining the real mechanism behind this, and evidence of causality is invariably small.

\section{Inflammation}

There is an important role of chronic inflammation in the pathophysiology of chronic diseases. Most of the diseases are a risk factor for CVD [17]. Depression is distinguished by a persistent inflammatory state, and increased levels of pro-inflammatory markers such as C-reactive 
protein (CRP), interleukin-6, and fibrinogen might have a role in conferring an elevated risk of CAD in patients with depression [18].

Several studies report an elevated level of CRP in patients with depression. A study in the Czech Republic enrolled 6,126 people. It demonstrated that people with depressive symptoms had a higher concentration of CRP than healthy controls [19]. In a similar Finnish study, depression measured by the Beck Depression Inventory was related to increased CRP $(p<0.001)$ [20]. These findings confirm a positive relationship of depression as a trigger to $\mathrm{CAD}$.

\section{A Change in Platelet Reactivity}

Platelets are a contributor to arterial wall repair and maintain the integrity of the vascular system by attachment of the endothelial stem cells. However, with a sustained inflammatory state, platelet function abates with time and age-related depletion, resulting in the recruitment of inflammatory cells which contribute to atherosclerotic plaque formation in the intima of blood vessels [21]. When platelets are activated by an injured arterial wall, they induce a chemokine-dependent recruitment of macrophages which induce apoptosis of intimal cells in the arteries. The apoptosis leads to arterial wall weakening, which promotes elevated free radicals that induce smooth muscle migration inside the intima. Smooth muscle proliferation inside the intima causes narrowing of the arterial lumen by protrusion of the atheroma and compensatory positive remodeling, causing dilatation of the arterial conduit [22]. The role of platelet thrombosis and the recruitment of smooth muscle proliferation should be investigated in depression.

In one study, patients with depression had a significant activation of platelets, demonstrated by P-selectin-positive platelets as compared with controls. They also had more platelet-leukocyte aggregates than controls $(p<$ 0.001 ) [23]. One in vitro study demonstrated an increased platelet reactivity to adenosine diphosphate in patients with depression [23]. This further enforces the hypothesis of platelet activation in depression.

Activated platelets release beta-thromboglobulin and platelet factor 4 into the circulation. One study confirms these findings in elderly patients $(n=21)$ with depression who were prophylactically treated with aspirin [24]. However, a larger Heart and Soul Study negated any elevation of beta-thromboglobulin and platelet factor 4 in 104 patients with CAD and depression [25].

\section{Role of Endothelial Dysfunction}

There is a role of endothelial dysfunction in chronic inflammatory disease and acute infections like COVID-19. A meta-analysis showed an inverse relationship of endothelial function with depression [26].

A hypothesis suggests an oxidative insult on lipids which can lead to atherosclerosis of the coronary arteries and is, therefore, a potential risk factor for CAD in patients with depression. Markers of oxidative stress to lipids were found to be elevated in a couple of studies that enrolled patients of CAD with depression [27].

Macrophages secrete endothelin-1, which is thought to be involved in atherosclerosis leading to ACS. In one cross-sectional study, endothelin-1 was found to be positively correlated with Beck's Depression Index score. However, no causality was drawn due to the cross-sectional nature of the study [28].

\section{Chronotropic Response of the Heart}

A positive chronotropic response is the ability of the heart to respond to various stimuli in our daily routine, and it reflects a healthy sympathetic system [4]. Another term used for a chronotropic response is heart-rate variability (HRV). A decreased HRV is associated with depression, anxiety, and increased mortality. This can be because of the poorly functioning anti-inflammatory cholinergic reflex. In an ELSA-Brasil Cohort Baseline Study, a decreased HRV was seen in patients not taking antidepressants [29]. Similarly, in 1 study post-MI, depressed patients showed a decreased HRV, suggesting that a lower HRV can mediate the adverse effects of depression in patients with CAD [30]. The Heart and Soul study confirmed this phenomenon among depressed patients [25].

\section{Endocrine Factors}

There is a definite link between hypothyroidism, whether subclinical or overt, and increased risk of CVDassociated morbidity and mortality. In patients with depression, there is an increased propensity for subclinical hypothyroidism [31]. However, no studies have been conducted to prove a direct association between CAD and the hypothalamus-pituitary-thyroid axis.

On the contrary, of all the pathophysiological disturbances in depression, the hypothalamus-pituitary axis is widely studied in the literature. Almost all patients with low mood exhibit elevated levels of plasma cortisol concentrations and increased adrenocorticotrophic hormone and beta-endorphin levels [32]. Elevated serum cortisol levels are associated with CVD mortality. In a 
CHIANTI prospective cohort study, elevated urinary cortisol levels predicted the risk of cardiovascular mortality [33]. Further investigations are needed to find a link between the hypothalamus-pituitary axis with CAD outcomes and depression.

\section{Treatment Modalities}

Tricyclic antidepressants (TCA) are not used as firstline agents in depression because of their cardiovascular adverse effects. By contrast, selective serotonin reuptake inhibitors (SSRIs) are generally well tolerated in such patients. However, in one study of 136,293 elderly women with depression, SSRIs were associated with an increased incidence of hemorrhagic stroke and fatal MI. However, the absolute risk of adverse events was low in patients taking SSRIs [34]. On the contrary, a meta-analysis concluded that TCA mirtazapine and SSRI citalopram were safe in patients with CAD [2].

Other nonpharmacological modalities of treatment include somatic treatments (electroconvulsive therapy, vagus nerve stimulation, and deep brain stimulation) and psychotherapies (cognitive behavioral therapy and personalized psychotherapy). MIND-IT and ENRICHD were 2 large multicenter trials that aimed at assessing the efficacy of TCAs with SSRIs and cognitive behavioral therapy, respectively $[35,36]$. Several studies have demonstrated a combination of antidepressant and cognitive behavioral therapy to improve symptoms of depression without ameliorating cardiac symptoms [37, 38]. One study randomized 240 patients with MI to either an SSRI or a placebo. It showed that prophylactic SSRI can prevent post-MI patients from developing symptoms of depression [39]. These findings are confirmed by another randomized interventional trial (COPES) [40]. A study of 362 patients with CVD showed a $41 \%$ reduction in fatal and nonfatal $\mathrm{MI}$ in patients given cognitive behavioral therapy. However, in this study, cognitive behavioral therapy was used for stress management rather than depression [41].

In one randomized controlled trial of 284 patients with CAD and depression, citalopram was superior to placebo, while cognitive therapy was nonsuperior to clinical management [42]. In another study, 110 participants of a nursing home demonstrated a $60 \%$ reduction in cardiovascular events in patients on citalopram [43].

A decrease in levels of lipoprotein (a) was observed in 21 patients treated with paroxetine but not amitriptyline [44]. On the other hand, cognitive behavioral therapy did not decrease patients' CRP or cortisol levels [12].

\section{Conclusion}

Depression and CVD impart a socioeconomic burden worldwide. Depression alone is a big health concern that is inadequately addressed. In addition to CVD, depression can adversely affect the cardiovascular system, which can lead to an elevated risk of morbidity and mortality. The cumulative literature suggests that timely treatment and prevention of depression in CVD can improve both quality of life and longevity. Although the new data suggest a positive relationship between CVD and depression, the exact mechanism behind this is only hypothetical. Increased inflammation might contribute to CVD and depression in all age-groups. Inflammatory markers are markedly increased in patients with depression, which weakens the arterial integrity. As a consequence, atherosclerosis is accelerated in the inflamed arteries, leading to cardiovascular events. Although antidepressants and cognitive behavioral therapy seem to be the mainstay of treatment in patients with depression, further large-scale studies should be done to clarify the mechanism of CVD in depression and outcomes of other pharmacological and nonpharmacological treatments. Studies focused on precursors of inflammation can further clarify the missing link between CVD and depression. Results of these studies can help us understand why a "breaking heart" can lead to a "failing heart."

\section{Conflict of Interest Statement}

The authors have no conflicts of interest to disclose.

\section{Funding Sources}

The authors did not receive any funding.

\section{Author Contributions}

Jahanzeb Malik: concept, methodology, critical review and final draft, and supervision. Hamid Sharif Khan: first draft and final draft writing. Faizan Younus: methodology, critical review, and final draft writing. Muhammad Shoaib: first draft and methodology. 


\section{References}

1 Halaris A. Comorbidity between depression and cardiovascular disease. Int Angiol. 2009; 28(2):92-9.

2 Dowlati Y, Herrmann N, Swardfager WL, Reim EK, Lanctôt KL. Efficacy and tolerability of antidepressants for treatment of depression in coronary artery disease: a meta-analysis. Can J Psychiatry. 2010;55(2):91-9.

3 Garfield LD, Scherrer JF, Hauptman PJ, Freedland KE, Chrusciel T, Balasubramanian $\mathrm{S}$, et al. Association of anxiety disorders and depression with incident heart failure. Psychosom Med. 2014;76(2):128-36.

4 Nemeroff CB, Goldschmidt-Clermont PJ. Heartache and heartbreak-the link between depression and cardiovascular disease. Nat Rev Cardiol. 2012;9(9):526-39.

5 Davidson KW, Alcántara C, Miller GE. Selected psychological comorbidities in coronary heart disease: Challenges and grand opportunities. Am Psychol. 2018;73(8):1019_ 30.

6 Headrick JP, Peart JN, Budiono BP, Shum DHK, Neumann DL, Stapelberg NJC. The heartbreak of depression: 'Psycho-cardiac' coupling in myocardial infarction. J Mol Cel Cardiol. 2017;106:14-28.

7 Thombs BD, Ziegelstein RC, Parakh K, Stewart DE, Abbey SE, Grace SL. Probit structural equation regression model: general depressive symptoms predicted post-myocardial infarction mortality after controlling for somatic symptoms of depression. J Clin Epidemiol. 2008;61(8):832-9.

8 Beaulieu S, Saury S, Sareen J, Tremblay J, Schütz CG, McIntyre RS, et al. The Canadian Network for Mood and Anxiety Treatments (CANMAT) task force recommendations for the management of patients with mood disorders and comorbid substance use disorders. Ann Clin Psychiatry. 2012;24(1):38-55.

9 Ruan Y, Guo Y, Zheng Y, Huang Z, Sun S, Kowal P, et al. Cardiovascular disease (CVD) and associated risk factors among older adults in six low-and middle-income countries: results from SAGE Wave 1. BMC Public Health. 2018;18(1):778.

10 Holt RI, Phillips DI, Jameson KA, Cooper C Dennison EM, Peveler RC. The relationship between depression, anxiety and cardiovascular disease: findings from the Hertfordshire Cohort Study. J Affect Disord. 2013;150(1): 84-90.

11 Iosifescu DV, Clementi-Craven N, Fraguas R, Papakostas GI, Petersen T, Alpert JE, et al. Cardiovascular risk factors may moderate pharmacological treatment effects in major depressive disorder. Psychosom Med. 2005; 67(5):703-6.

12 Taylor CB, Conrad A, Wilhelm FH, Strachowski D, Khaylis A, Neri E, et al. Does improving mood in depressed patients alter factors that may affect cardiovascular disease risk?. J Psychiatr Res. 2009;43(16):1246-52.
13 Ford DE, Mead LA, Chang PP, Cooper-Patrick L, Wang NY, Klag MJ. Depression is a risk factor for coronary artery disease in men: the precursors study. Arch Intern Med. 1998; 158(13):1422-6.

14 Surtees PG, Wainwright NW, Luben RN, Wareham NJ, Bingham SA, Khaw KT. Depression and ischemic heart disease mortality: evidence from the EPIC-Norfolk United Kingdom prospective cohort study. Am J Psychiatry. 2008;165(4):515-23.

15 Kendler KS, Gardner CO, Fiske A, Gatz M. Major depression and coronary artery disease in the Swedish twin registry: phenotypic, genetic, and environmental sources of comorbidity. Arch Gen Psychiatry. 2009;66(8):85763.

16 Frasure-Smith N, Lespérance F, Habra M, Talajic M, Khairy P, Dorian P, et al. Elevated depression symptoms predict long-term cardiovascular mortality in patients with atrial fibrillation and heart failure. Circulation. 2009; 120(2):134-40.

17 Rocha VZ, Libby P. Obesity, inflammation, and atherosclerosis. Nat Rev Cardiol. 2009; 6(6):399-409.

18 Miller AH, Raison CL. The role of inflammation in depression: from evolutionary imperative to modern treatment target. Nat Rev Immunol. 2016;16(1):22-34.

19 Pikhart H, Hubacek JA, Kubinova R, Nicholson A, Peasey A, Capkova N, et al. Depressive symptoms and levels of C-reactive protein: a population-based study. Soc Psychiatry Psychiatr Epidemiol. 2009;44(3):217-22.

20 Elovainio M, Aalto AM, Kivimäki M, Pirkola S, Sundvall J, Lönnqvist J, et al. Depression and C-reactive protein: population-based Health 2000 Study. Psychosom Med. 2009; 71(4):423-30

21 Mause SF, Ritzel E, Liehn EA, Hristov M, Bidzhekov K, Müller-Newen G, et al. Platelet microparticles enhance the vasoregenerative potential of angiogenic early outgrowth cells after vascular injury. Circulation. 2010;122(5): 495-506.

22 Goldschmidt-Clermont PJ, Seo DM, Wang L, Beecham GW, Liu ZJ, Vazquez-Padron RI, et al. Inflammation, stem cells and atherosclerosis genetics. Curr Opin Mol Ther. 2010;12(6): 712-23.

23 Morel-Kopp MC, McLean L, Chen Q, Tofler $\mathrm{GH}$, Tennant C, Maddison V, et al. The association of depression with platelet activation: evidence for a treatment effect. J Thromb Haemost. 2009;7(4):573-81

24 Laghrissi-Thode F, Wagner WR, Pollock BG, Johnson PC, Finkel MS. Elevated platelet factor 4 and beta-thromboglobulin plasma levels in depressed patients with ischemic heart disease. Biol Psychiatry. 1997;42(4):290-5.
25 Gehi A, Musselman D, Otte C, Bruce Royster E, Ali S, Whooley MA. Depression and platelet activation in outpatients with stable coronary heart disease: findings from the Heart and Soul Study. Psychiatry Res. 2010;175(3): 200-4.

26 Cooper DC, Tomfohr LM, Milic MS, Natarajan L, Bardwell WA, Ziegler MG, et al. Depressed mood and flow-mediated dilation: a systematic review and meta-analysis. Psychosom Med. 2011;73(5):360-9.

27 Yager S, Forlenza MJ, Miller GE. Depression and oxidative damage to lipids. Psychoneuroendocrinology. 2010;35(9):1356-62.

28 Burg MM, Martens EJ, Collins D, Soufer R. Depression predicts elevated endothelin-1 in patients with coronary artery disease. Psychosom Med. 2011;73(1):2-6.

29 Kemp AH, Brunoni AR, Santos IS, Nunes MA, Dantas EM, Carvalho de Figueiredo R, et al. Effects of depression, anxiety, comorbidity, and antidepressants on resting-state heart rate and its variability: an ELSA-Brasil cohort baseline study. Am J Psychiatry. 2014;171(12): 1328-34.

30 Su S, Lampert R, Lee F, Bremner JD, Snieder $\mathrm{H}$, Jones $\mathrm{L}$, et al. Common genes contribute to depressive symptoms and heart rate variability: the Twins Heart Study. Twin Res Hum Genet. 2010;13(1):1-9.

31 Nemeroff CB, Simon JS, Haggerty JJ Jr, Evans DL. Antithyroid antibodies in depressed patients. Am J Psychiatry. 1985;142(7):840-3.

32 Jokinen J, Nordström P. HPA axis hyperactivity and cardiovascular mortality in mood disorder inpatients. J Affect Disord. 2009;116(12):88-92.

33 Vogelzangs N, Beekman AT, Milaneschi Y, Bandinelli S, Ferrucci L, Penninx BW. Urinary cortisol and six-year risk of all-cause and cardiovascular mortality. J Clin Endocrinol Metab. 2010;95(11):4959-64.

34 Smoller JW, Allison M, Cochrane BB, Curb JD, Perlis RH, Robinson JG, et al. Antidepressant use and risk of incident cardiovascular morbidity and mortality among postmenopausal women in the Women's Health Initiative study. Arch Intern Med. 2009;169(22): 2128-39.

35 Honig A, Kuyper AM, Schene AH, van Melle JP, de Jonge P, Tulner DM, et al. Treatment of post-myocardial infarction depressive disorder: a randomized, placebo-controlled trial with mirtazapine. Psychosom Med. 2007; 69(7):606-13.

36 Berkman LF, Blumenthal J, Burg M, Carney RM, Catellier D, Cowan MJ, et al. Effects of treating depression and low perceived social support on clinical events after myocardial infarction: the Enhancing Recovery in Coronary Heart Disease Patients (ENRICHD) Randomized Trial. JAMA. 2003;289(23): 3106-16. 
37 Thombs BD, de Jonge P, Coyne JC, Whooley MA, Frasure-Smith N, Mitchell AJ, et al. Depression screening and patient outcomes in cardiovascular care: a systematic review. JAMA. 2008;300(18):2161-71.

38 Taylor CB, Youngblood ME, Catellier D, Veith RC, Carney RM, Burg MM, et al. Effects of antidepressant medication on morbidity and mortality in depressed patients after myocardial infarction. Arch Gen Psychiatry. 2005;62(7):792-8.

39 Hansen BH, Hanash JA, Rasmussen A, Hansen JF, Andersen NL, Nielsen OW, et al. Effects of escitalopram in prevention of depression in patients with acute coronary syndrome (DECARD). J Psychosom Res. 2012; 72(1):11-6.

40 Davidson KW, Rieckmann N, Clemow L, Schwartz JE, Shimbo D, Medina V, et al. En- hanced depression care for patients with acute coronary syndrome and persistent depressive symptoms: coronary psychosocial evaluation studies randomized controlled trial. Arch Intern Med. 2010;170(7):600-8.

41 Gulliksson M, Burell G, Vessby B, Lundin L, Toss H, Svärdsudd K. Randomized controlled trial of cognitive behavioral therapy vs standard treatment to prevent recurrent cardiovascular events in patients with coronary heart disease: secondary Prevention in Uppsala Primary Health Care project (SUPRIM). Arch Intern Med. 2011;171(2):13440.

42 Lespérance F, Frasure-Smith N, Koszycki D, et al. Effects of citalopram and interpersonal psychotherapy on depression in patients with coronary artery disease: the Canadian Cardiac Randomized Evaluation of Antidepressant and Psychotherapy Efficacy (CREATE) trial [published correction appears]. JAMA. 2007; 297(4):367-79. Erratum in: JAMA. 2007 Jul 4; 298(1):40.

43 Santangelo A, Testaì M, Barbagallo P, Crisafulli C, Grasso S, Manuele S, et al. Use of specific serotonin reuptake inhibitors (SSRIs) (Sertraline or Citalopram) in the treatment of depression reduces the cardiovascular risk in the elderly: evidence from a Sicilian population $>80$ years recovered in the assisted sanitary residences (RSA). Arch Gerontol Geriatr. 2009;48(3):350-2.

44 Paslakis G, Kopf D, Westphal S, Gilles M, Lederbogen F, Hamann B, et al. Treatment with paroxetine, but not amitriptyline, lowers levels of lipoprotein(a) in patients with major depression. J Psychopharmacol. 2011;25(10): $1344-6$ 